\title{
\begin{tabular}{l|l} 
Mitraries & DSpace@MIT
\end{tabular}
}

\author{
MIT Open Access Articles
}

\author{
Motivating Sustainable Behavior Using \\ Cognitive Interventions in Product Design
}

The MIT Faculty has made this article openly available. Please share how this access benefits you. Your story matters.

Citation: Saadi, Jana I and Yang, Maria C. 2020. "Motivating Sustainable Behavior Using Cognitive Interventions in Product Design." Proceedings of the ASME Design Engineering Technical Conference, 8.

As Published: 10.1115/DETC2020-22464

Publisher: ASME International

Persistent URL: https://hdl.handle.net/1721.1/139759

Version: Final published version: final published article, as it appeared in a journal, conference proceedings, or other formally published context

Terms of Use: Article is made available in accordance with the publisher's policy and may be subject to US copyright law. Please refer to the publisher's site for terms of use. 
Proceedings of the ASME 2020

International Design Engineering Technical Conferences and Computers and Information in Engineering Conference

IDETC/CIE2020

August 17-19, 2020, Virtual, Online

DETC2020-22464

\section{MOTIVATING SUSTAINABLE BEHAVIOR USING COGNITIVE INTERVENTIONS IN PRODUCT DESIGN}

\author{
Jana I. Saadi \\ Department of Mechanical Engineering \\ Massachusetts Institute of Technology \\ Cambridge, MA
}

\author{
Maria C. Yang \\ Department of Mechanical Engineering \\ Massachusetts Institute of Technology \\ Cambridge, MA
}

\begin{abstract}
Designing products to encourage sustainable behavior during their use can have significant influence on their total environmental impact. Cognitive interventions can be used to inform users of the importance of sustainable behavior and make users aware of the resources they consume while evoking positive or negative emotions. The first part of this study investigated two methods of cognitive interventions, information (positively and negatively framed) and feedback, and their effectiveness in encouraging users to reduce their napkin consumption in cafés. The number of napkins per transaction illustrated a short-term behavior change for positive information, a longer-term behavior change for negative information, and no change for feedback. In the second phase of this study, a survey was conducted to understand environmental concerns around napkin consumption and emotions and perceived effectiveness of each intervention. Results from 295 valid survey responses showed that the positively framed informative design reminded users to use less napkins in order to save trees and was dominated by positive emotions such as feeling encouraged. The negative information message informed users to use fewer napkins due to the consequences on the environment and was related to negative emotions such as guilt and worry. The feedback intervention's message was more informative, reminding users that napkins come from trees and the emotions evoked from the intervention closely resembled that of the control. These findings suggest that information and feedback interventions that evoke emotions can be used to promote sustainable behavior.
\end{abstract}

\section{INTRODUCTION}

Products incur environmental impacts through all stages of their life cycle, from materials selection and processing, to product retirement. Designers can reduce the environmental footprint of products by influencing decisions made in each stage of the life cycle. While it is important to consider methods to better a product's sustainability through its creation and end of life phases, there is also great potential for improvement through the user interaction with the product, known as the use phase [1]. For instance, energy consumption for electrical products in their use phase accounts for $60-80 \%$ of their environmental impact [1]. User perceptions of sustainability in the use phase may also have unintended consequences. Some paper napkins, for example, are made from $100 \%$ recycled materials, making them more sustainable for the environment. However, people may take more napkins than necessary because of the mindset that these napkins are friendlier to the environment. The environmental benefits of material selection for napkins can thus be offset by a user's over consumption of napkins, a problem known as the rebound effect [2].

Due to the increased environmental impact of products in their use phase, which can be compounded by influences such as the rebound effect, improving a product's sustainability during use can have extensive influence on its overall environmental impact. One method to reduce the environmental impact of a product is to design the product to encourage the user to interact with the product more sustainably [1]. This approach is used by the emerging field of Design for Behavior Change, which focuses on the idea that the design of a product can impact user behavior [3]. Sohn, et al. identified two types of product interventions: cognitive interventions and physical interventions [4]. Cognitive interventions influence a user's decision-making process in order to motivate sustainable behavior, and commonly take the form of information (giving user related information) or feedback (reminding users of resource usage). From a dual process theory perspective, these methods are used to transform user's decision making process from a subconscious and instinctive Type 1 thinking to a more conscious and analytical Type 2 thought process in order to motivate behavior change. [5] Physical interventions in products change behavior by constraining or enabling functions, such as a water faucet that turns off automatically. Unlike physical interventions, cognitive interventions have the advantages of being less intrusive [1], easier to implement [6], and can raise environmental awareness that leads to a spill-over of environmentally friendly behavior [7].

This study seeks to understand how products can be designed to encourage sustainable behavior through their use. Three main questions are explored:

Q1: What are the immediate and longer-term effects of information and feedback interventions on user behavior?

We seek to understand how different cognitive interventions influence user behavior over time. We predict that while these 
cognitive interventions may result in short-term sustainable behavior, their effectiveness in encouraging behavior change may decrease over time [8,9].

Q2: What role do positive, negative, and neutral emotions have in influencing users' sustainable behavior?

We are interested in understanding how a user's emotions influence their behavior with respect to resource consumption. We want to assess whether emotionally rich products designed with information and feedback interventions can promote sustainable behavior. We expect that interventions that evoke strong emotions are more likely to encourage behavior change compared to interventions that do not [10].

Q3: How effective are positively framed and negatively framed messages in influencing sustainable resource consumption?

Information from cognitive interventions can be framed in a number of ways, but the most common strategy is to phrase information as positive ("turning off your lights saves energy") or negative ("leaving your lights on is wasteful"). We would like to compare the perceived effectiveness of a positively framed informative message versus a negatively framed informative message in encouraging behavior change, specifically for resource consumption.

These questions were investigated in the context of motivating users to reduce their paper napkin consumption by implementing different cognitive interventions in the designs of napkin dispensers. The effects of the interventions on user behavior was observed in a real-world setting over an eight-week period. A separate survey was conducted to more deeply understand user perceptions of these types of interventions.

\section{BACKGROUND}

\subsection{Interventions for Sustainable Behavior}

Research around design for behavior change has focused on developing interventions, or stimuli to encourage sustainable practice, using product design [4]. Several interventions for how a product can be used to promote behavior change are outlined in the literature. Boks, et al summarized the main design frameworks which seek to reduce the environmental impact of products during their use phase [11]. Prevailing techniques fall on a spectrum of user-in-control to product-in-control. The interventions along this range differ mainly in terms of the level of cognitive load and how much control is given to the user. The division of control along this spectrum is summarized with three terms: informing, persuading and determining [12]. At the informing end of the scale, the user receives information or feedback about their behavior and has total control over the decision-making process. At the persuading part of the spectrum, the user remains in control, but the product takes some of the control by making the desired behavior more intuitive or the undesired behavior harder. The determining end of the spectrum puts all the control with the product, blocking certain user behaviors or automatically performing the desired behavior.

Previous studies investigated the effectiveness of different strategies and the users' perception of the designs. For instance, Montazeri, et al. created three napkin dispensers that displayed the number of napkins remaining using different eco-feedback designs. Through a field study they found that these metaphor based eco-feedback designs were effective in reducing resource consumption while the interventions where in place [13]. In another study, they used an in-lab experiment to investigate the effect of color of recycling bins on encouraging recycling behaviors [14]. Cor and Zwolinski conducted an in-lab experiment to test four coffee makers intended to encourage electricity conservation. They found that designs that gave feedback on the amount of energy consumed (eco-feedback) and set a target value for energy consumption (goal setting) were perceived as more useful and less intrusive compared to coffee makers that automatically turned off (forcing technology) [1]. Sohn, et al. tested the immediate reactions of users with 10 faucet and sink designs with different interventions. From the strategies they tested, those that displayed feedback on water usage were more effective in encouraging water conservation than physical interventions [4]. Other studies looked specifically at providing feedback in energy meters and washing machines which showed that providing feedback and goal-setting were successful in motivating sustainable behavior $[15,16]$. A survey-based study conducted by Bao, et al. emphasized the importance of both the quantitative clarity and the strength of emotion evoked in designing eco-feedback interventions [17]. In another controlled lab study, they investigated the emotional responses related to different quantitative and figurative eco-feedback designs [10].

Most of the studies above test different interventions through in a controlled lab setting $[1,4,10,15-18]$. Others tested the effectiveness of a single intervention in a real-world setting [13]. Additionally, most of the research only monitored the immediate effects of the intervention and did not investigate any longer-term effects present over a few weeks [19]. In this study, different cognitive interventions, information and feedback, to encourage sustainable behavior are explored in real world settings, and their effectiveness is observed over several weeks to evaluate their longer-term effects. Monitoring user behavior in a real-world setting allows for the observation of actual user behavior and how it changes over a period of several weeks, rather than their perceptions or immediate behaviors obtained through surveys and lab experiments.

\subsection{Positive and Negative Message Framing}

Another aspect in which cognitive interventions can differ is the message framing. Negative framed messages convey the losses associated with the behavior while positively framed messages focus on obtaining gains [20]. These have also been referred to as the 'sick baby' appeal, which stresses the importance and severity of an issue, and the 'well baby' appeal, which conveys the significance of individual action [21]. Obermiller's research shows that the effectiveness of the message framing depends on the relative issue salience, or the perceived importance and concern of the problem [21]. A sick baby appeal presents the problem as severe and important, which should increase attention to the message, evoke emotional responses, and increase overall concern for the issue [21]. Therefore, if prior perceived importance is low, then a negatively 
framed message will illustrate the gravity of the issue and increase the concern for the issue. However, if prior concern is already high then a negatively framed message will make the situation seem hopeless [20]. In this case of a high prior concern, a well baby appeal will bolster the belief that an individual's actions can have an effect [21]. Therefore, a positively framed message will be more successful when prior issue salience is high, while a negatively framed message will be more effective in influencing behavior when prior salience of the issue is low [21]. This relationship is shown in several studies examining the effectiveness of message framing for issues of energy, water, waste reduction and recycling [20,21].

\section{METHODS}

In the first phase of this study, the behavior of users was observed in response to napkin dispensers featuring different interventions in three different cafés on a US university campus. The number of napkins used per customer was monitored over several weeks to serve as an indicator of sustainable behavior. This method allowed for observation of real-world behavior of users as opposed to interviews, which may not be accurate predictors of behavior as people may say what they believe to be more socially acceptable [15]. While the field experiment measured the aggregate effectiveness of each intervention in promoting sustainable behavior, it could not explain the reasoning behind the user behavior. Therefore, in phase 2 of this study, a survey was conducted to better understand the emotions and perceptions behind each intervention

\subsection{Dispenser Designs}

The three interventions chosen were positive information, negative information and feedback. The exact form of these interventions took into consideration several factors in their messaging and design. In order to design the dispensers with the information and feedback interventions, techniques from behavioral psychology were used. There are seven persuasive metaphor heuristics used by designers to motivate behavior: give an informative message, use a slogan, create a feeling (such as reward or punishment), exaggerate the scale of impact, show final impact of behavior, interactive design, and dynamic design [13]. After generating several possible designs based on these heuristics and obtaining feedback from several graduate students, peers, and café management, three designs were created in collaboration with a professional product designer as shown in Figure 1. The positive informative message states: "If you use one less napkin, we could save 544,000 trees a year" [22]. This gives an informative message while creating the feeling of a positive reward for the behavior on the environment and showing the potential impact of the desired behavior of using fewer napkins. The negative informative message states: "25 million trees cut for napkins each year" [23,24]. This gives an informative message while showing the implications of the current behavior. The feedback design shows an image of a tree, with the main trunk and branches cut out so that the current level of napkins can be seen from within. As users consume more napkins, the tree depletes. This metaphorical strategy of feedback with visual representation has been used before, illustrating to the users the amount of napkins that are being used while relating it to an environmental setting $[13,17,25]$. This strategy exaggerates the impact of napkin usage on the environment since a single tree can make more than the number of napkins shown in the dispenser.

Commercial stand napkin dispensers shown in Figure 1 were modified with the three designs to represent information and feedback interventions. The dispensers have a capacity of 1000 napkins and dispense one napkin at a time. These dispensers are widely used in the US and were likely familiar to users.

To maximize the intervention's potential for changing behavior, the message had to be easy to understand and believable, presented in a way that catches the user's attention, be memorable, and delivered as closely as possible to the time and location of the behavioral choice [26]. To ensure that the designs on the dispensers were noticeable, the messages covered the entire front panel of the napkin dispenser, with the most important information printed in a larger font at eye level. Placing the messages directly on the dispensers also ensured that the user could see the message as they were taking napkins, giving them the immediate chance to change their behavior.

There are four main attributes for cognitive interventions such as information and feedback: interpretation, orientation, representation fidelity and degree of exposure [4]. For this study, it is important that these four attributes remain similar across the different interventions in order to eliminate any effects they may have on behavior. Research on the design of cognitive interventions suggests that realistic graphics are more effective than abstract expressions [4]. Colorful backgrounds with animation can attract more human interest [25]. The study's designs were created in collaboration with a professional product designer to ensure consistency among the styles of the design $[27,28]$. Interventions used in this study were designed to be as similar as possible across all attributes, using realistic and colorful images in the background to help convey the message.

\subsection{Field Study}

In total, four different dispensers were used, a dispenser with the default manufacturer message as the control and three dispensers designed with the interventions as shown in Figure 1. The dispensers were each placed in different popular cafés serving coffee, drinks, baked goods, and casual lunch in the main part of campus, and the number of napkins used each day was collected over the span of eight weeks.

\subsubsection{Measuring Napkin Usage}

The three cafés all operated under the same management and had similar physical set-ups. Additionally, the cafés were all located in areas with moderate foot-traffic.

The experiment was split up into three stages as shown in Figure 2. In the first stage, control dispensers with the default manufacturer message were placed in each of the three cafés for two weeks. This established the baseline for normal napkin usage in each café. In the second stage, each dispenser with a 

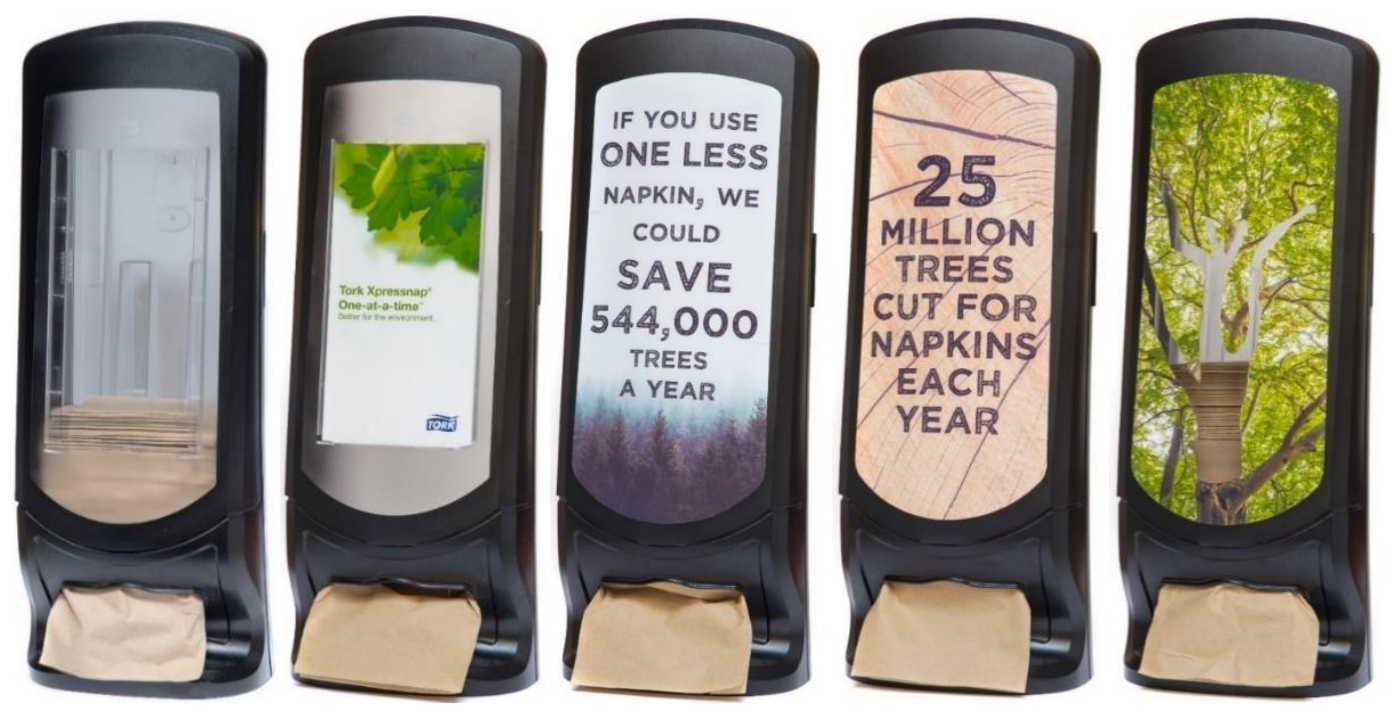

FIGURE 1: NAPKIN DISPENSER DESIGNS FROM LEFT TO RIGHT: BLANK (SURVEY CONTROL) MANUFACTURER DEFAULT (FIELD CONTROL), POSITIVE INFORMATION, NEGATIVE INFORMATION, FEEDBACK.

different intervention was each put into a different café, and napkin usage was monitored over three and a half weeks. Finally, the default dispensers were again placed in the cafés for two and a half weeks. This allowed any longer-term effects on behavior from the interventions to be observed. The timing of each stage was carefully planned to avoid campus holidays, ensuring that day of data collection was a full day of work and classes.

\begin{tabular}{|l|l|l|}
\hline $\begin{array}{l}\text { Establish } \\
\text { baseline: Install } \\
\text { default (control) } \\
\text { napkin } \\
\text { dispensers and } \\
\text { monitor daily } \\
\text { napkin usage. }\end{array}$ & $\begin{array}{l}\text { Observe effects } \\
\text { of intervention: } \\
\text { Install napkin } \\
\text { dispensers with } \\
\text { interventions and } \\
\text { monitor daily } \\
\text { napkin usage. }\end{array}$ & $\begin{array}{l}\text { Observe effects } \\
\text { after intervation } \\
\text { is removed: } \\
\text { Install default } \\
\text { napkin } \\
\text { dispensers and } \\
\text { monitor daily } \\
\text { usage. }\end{array}$ \\
\hline Control & $\begin{array}{l}\text { Intervention } \\
3.5 \text { weeks }\end{array}$ & $\begin{array}{l}\text { Post Control } \\
2.5 \text { weeks }\end{array}$ \\
\hline
\end{tabular}

\section{FIGURE 2: TIMELINE OF EXPERIMENT TO OBSERVE} NAPKIN CONSUMPTION BEHAVIOR IN CAFES.

The number of napkins used was determined by counting the number of pre-packaged napkin bundles (500 napkins each) placed in the dispenser and measuring the height of the remaining stack of napkins in the dispenser every 24-hour period. Each inch of napkin height is equivalent to an average of 55.9 napkins, determined by averaging several manually counted measurements of napkins/inch.

The number of cash register transactions per week was used as a proxy for the number of customers to calculate the average number of napkins used per person each day. Our observations suggest that this was a reasonable approximation as most transactions tended to be for individuals. Since the café management only collects the number of transactions per week for each café, the distribution of customers was assumed to be equal over the week in order to determine the average number of customers per day. This assumption that the number of customers per day is relatively constant throughout the week was verified upon several hours of personal observation of each café and through interviews with café staff.

\subsection{Survey}

A separate online survey was conducted to more deeply understand the perceived messages and emotions related to each intervention. The survey included images of dispensers with five different messages: no message, default manufacturer message, positive information, negative information and feedback as shown in Figure 1. Responses related to the perceived environmental concern of napkin consumption as well as the emotions, perceived message and effectiveness for each intervention were collected. A set of pilot surveys and in-person interviews were conducted with seven design graduate students and professionals to refine the survey questions. The final survey responses were collected using Amazon Mechanical Turk, a human intelligent crowdsourcing platform.

\subsubsection{Control Dispensers}

Two different dispensers representing the controls for the field study and the survey were compared in the survey: a dispenser with the default manufacturer sticker and a blank dispenser as shown in Figure 1. Initially, the survey only included the dispenser with the default manufacturer message as the control in order to remain consistent with the field study. However, pilot testing of the survey showed that the questions primed users to look closely at the dispenser design to read the 
text and observe the images of green leaves, which can imply environmental friendliness. It was observed that respondents were drawing conclusions about the dispenser with the default manufacturer message that they probably would not have done had they encountered this dispenser in person. In person interviews with users during the pilot survey test verified that they were unlikely to notice the default message in a real setting. Therefore, a blank dispenser was also added to represent the control for the survey. In this way, the blank dispenser in the survey served the same function of a baseline as the napkin dispenser with the manufacturer's message did in the café setting.

\subsubsection{Survey Quality Control}

In order to ensure quality of responses, only respondents with $99 \%$ approval rating and master status on Mechanical Turk were allowed to complete the survey. Respondents were compensated $\$ 1.25$, which was determined based on the predicted time to complete the survey and the federal minimum wage at the time of the study. The survey also included two quality control questions. The first question proceeded a description of the survey to ensure respondents are reading through the survey. The second question asked respondents to select a certain answer, ensuring that the respondents are not randomly selecting answers. Only responses with both quality control questions answered correctly were accepted.

\subsubsection{Environmental Concern}

In order to evaluate the effectiveness of the positive and negatively framed informative message, the users' baseline environmental concern was evaluated using a scale described below. If environmental concern is high, then it is expected that the positively framed message would be more effective. On the other hand, if the environmental concern is low, then the negative message would illustrate the gravity of the situation and would therefore be more effective [20,21].

The start of the survey included five questions around environmental concern related to napkin consumption. These questions were adapted from previous studies measuring prior concern [20,21,29]. The questions measure respondents' opinions on the impact of napkin consumption, the environmental effect, the potential seriousness of napkin consumption on the environment, the personal effect of napkin consumption, and their consideration of daily consumption of napkins. The questions were answered on a Likert scale of 0-4: strongly disagree, disagree, neutral, agree, and strongly agree.

\subsubsection{Measuring Emotions}

The method of self-reporting was used to measure human emotion. The Positive Affect and Negative Affect Scale (PANAS) is a tool used to measure the intensity of positive and negative emotions in people [30]. It contains a 20 -word scale with ten positive verbal descriptors, such as excited and enthusiastic, and ten negative verbal descriptions to measure emotions such as anger, guilt and fear. Another set of 175 emotion words are used to represent the range of emotions related to a consumer's consumption experience. This set of words was narrowed down to 47 total descriptions making up the list of Consumption Emotion Descriptions (CES) [31].

For each dispenser, participants self-reported the emotions they felt and their intensity [10,30]. Eleven emotions were evaluated: interested, worried, upset, guilty, proud, frustrated, encouraged, joyful, surprised, satisfied and, skeptical. These words were selected from the PANAS and CES word sets, and pilot tested for their appropriateness and ability to map the range of emotions felt in the napkin consumption scenario. This word set was intended to consist of both positive and negative emotion descriptors and was related to respondents' consumption experience and resource conservation behavior. The number of descriptors was chosen to sufficiently describe possible emotions related to each scenario while also avoiding survey fatigue by presenting too many descriptors. Participants reported to what extent they felt each emotion on a Likert scale of 0-4: not at all, slightly, moderately, strongly, and extremely. The sequence in which the emotions were presented was randomized.

\subsubsection{Perceived Message}

The perceived message of each dispenser design was asked through an open-ended question in the survey. This allowed respondents to reflect on the message they personally received from each dispenser design without any prior bias.

\subsubsection{Effectiveness, Perceived Consumer Effectiveness and Design Evaluation}

The survey also included a question with each dispenser to evaluate the general design of the message. Respondents were also asked two questions about the perceived effectiveness of each dispenser message. These questions were taken from previous studies and were used to evaluate effectiveness (how effective the intervention would be in changing their own behavior) and perceived consumer effectiveness (how effective the intervention would be in changing other peoples' behavior) $[20,21,29]$. These questions were answered on a scale of 0-4: not at all, slightly, moderately, strongly, and extremely.

\section{RESULTS 4.1 Field Study}

The average number of napkins used per transaction for each of the three cafés was determined based on the number of napkins used each day and the number of transactions per day in each café. Outliers in the data were determined based on quartile range. Days in which the napkin usage was higher than the upper bound, or below the lower bound were assumed to be abnormal occurrences. While the exact cause of the irregular usage is unknown, possible explanations include spilt coffee that needed more napkins to clean up or an incorrect recording by café staff of the number of napkin stacks placed in the dispenser. The weeks at each stage were used to produce the average number of napkins used per transaction for the control, intervention, and post-control stages for the positive information, negative information and feedback intervention, shown in Figure 3. 
Positive Information

Napkin Usage of Each Week

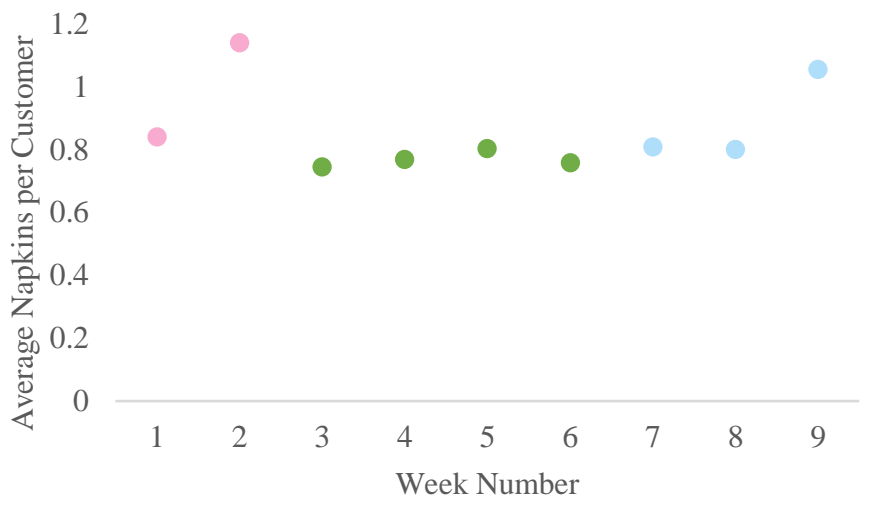

Negative Information

Napkin Usage of Each Week

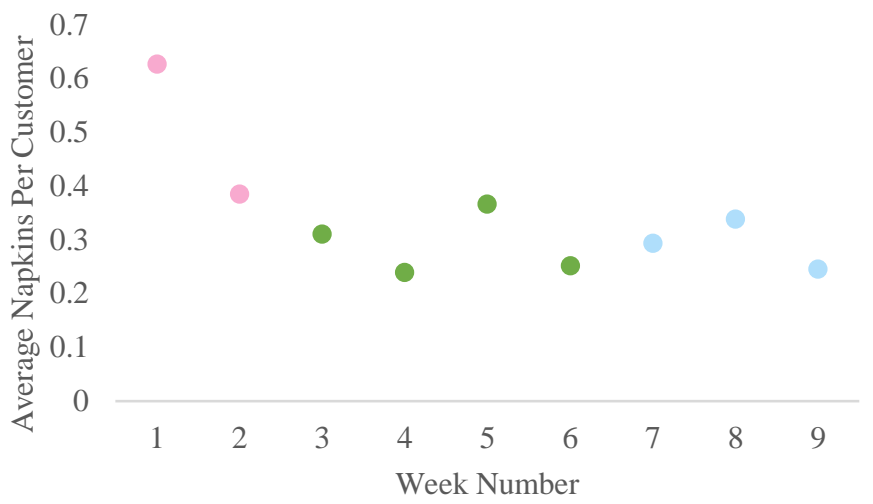

Feedback

Napkin Usage of Each Week

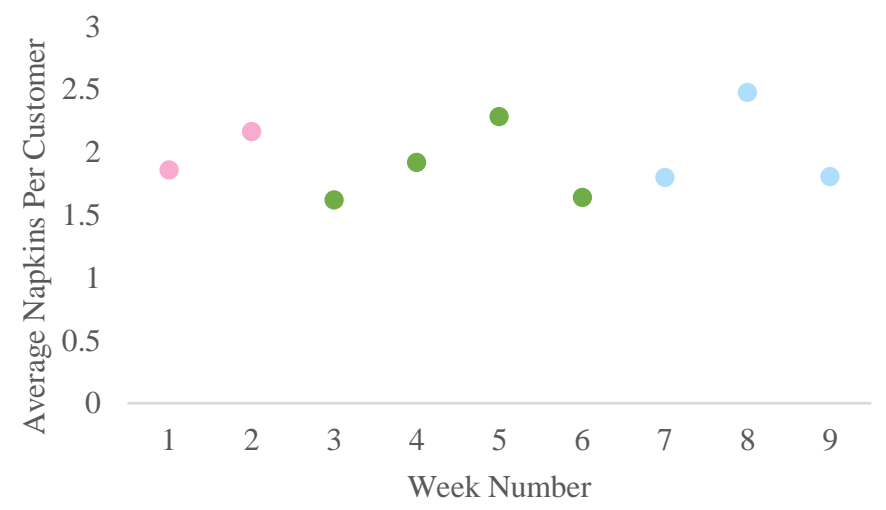

Positive Information

Napkin Usage of Each Stage

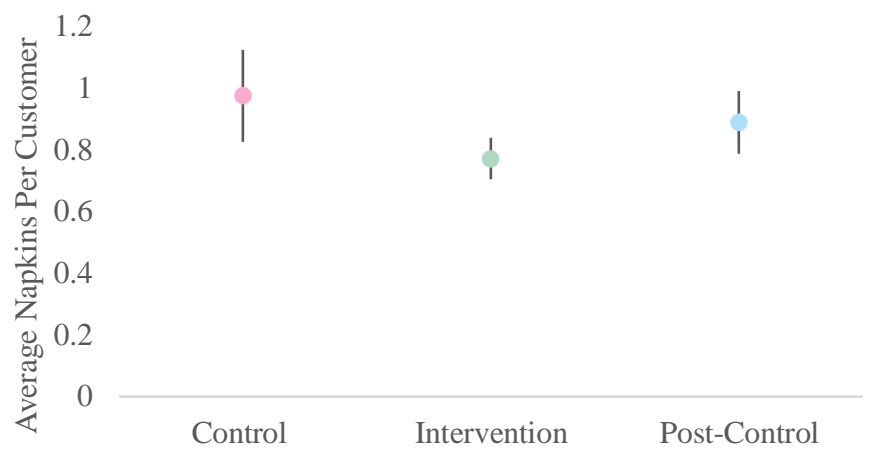

Negative Information

Napkin Usage of Each Stage

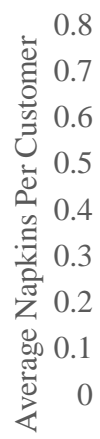

Control Intervention Post-Control

Feedback

Napkin Usage of Each Stage

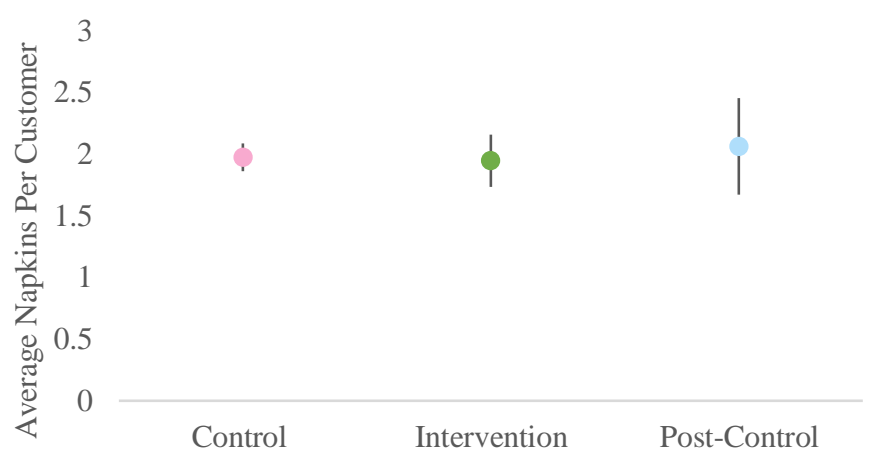

FIGURE 3: GRAPHS OF INDIVIDUAL WEEKLY NAPKIN CONSUMPTION AND AVERAGE CONSUMPTION OF THE THREE STAGES OF THE EXPERIMENT FOR THE DIFFERENT INTERVENTIONS. THE DIFFERENT COLOR DOTS REPRESENT THE DIFFERENT STAGES: PINK FOR CONTROL, GREEN FOR INTERVENTION, AND BLUE FOR POST CONTROL. THE DOTS AND THE ERROR BARS REPRESENT THE AVERAGE NAPKIN CONSUMPTION AND THE 95\% CONFIDENCE INTERVAL RESPECTIVELY. 
Since the three interventions were tested in parallel in different locations, conclusions on the effectiveness of the dispensers can only be drawn on an individual level and the interventions cannot be compared to each other. A Welch's t-test was conducted to determine any statistical differences of napkin usage between the three stages: control, intervention and postcontrol. The $\mathrm{p}$-values of the t-test for each of the interventions are summarized in Table 1.

TABLE 1: P-VALUES FOR THE WELCH'S T-TEST BETWEEN THE THREE DIFFERENT STAGES OF THE EXPREIMENT. SIGNIFICANT DIFFERENCES ON 0.05 LEVELS ARE HIGHLIGHTED IN GRAY.

\begin{tabular}{|l|c|c|c|}
\hline & $\begin{array}{c}\text { Positive } \\
\text { Information }\end{array}$ & $\begin{array}{c}\text { Negative } \\
\text { Information }\end{array}$ & Feedback \\
\hline $\begin{array}{l}\text { Control- } \\
\text { Intervention }\end{array}$ & 0.0166 & 0.0475 & 0.4111 \\
\hline $\begin{array}{l}\text { Intervention- } \\
\text { Post Control }\end{array}$ & 0.0371 & 0.2792 & 0.3354 \\
\hline $\begin{array}{l}\text { Control -Post } \\
\text { Control }\end{array}$ & 0.1824 & 0.0310 & 0.3381 \\
\hline
\end{tabular}

The positive information intervention showed a $22.3 \%$ decrease in napkin usage once the dispenser with the intervention was put in place. However, once the dispenser was removed the napkin usage once again increased and was statistically equal to the napkin usage before the intervention was placed. This illustrates a short-term effect for the positive information intervention. For the negative information intervention, the napkin usage decreased with the placement of the intervention by $42.3 \%$ and remained statistically lower than baseline after the intervention was removed. This shows both a short-term effect for the negative information intervention, as well as a potential learning effect which resulted in longer-term behavior change as well. The feedback intervention showed no statistically significant change of napkin usage between the three stages.

\subsection{Survey}

In total, 321 completed responses were collected through Amazon Mechanical Turk, and 295 responses passed all quality control questions.

\subsubsection{Environmental Concern}

The responses to the five initial questions gauging environmental concern, graphed in Figure 4, show that the concern for the effect of napkin consumption on the environment exists but it is not high. $67.1 \%$ of respondents strongly disagreed, disagreed or were neutral that the potential seriousness of the effect of napkin consumption is frightening. Over half of respondents $(52.2 \%)$ disagreed or were neutral about the personal effect of paper napkin consumption on their individual lives. Similarly, $54.2 \%$ of respondents were neutral about or did not consider their daily consumption of napkins. However, $66.8 \%$ and $54.6 \%$ of respondents did agree that it is important to consider the impact of napkin consumption on the environment,

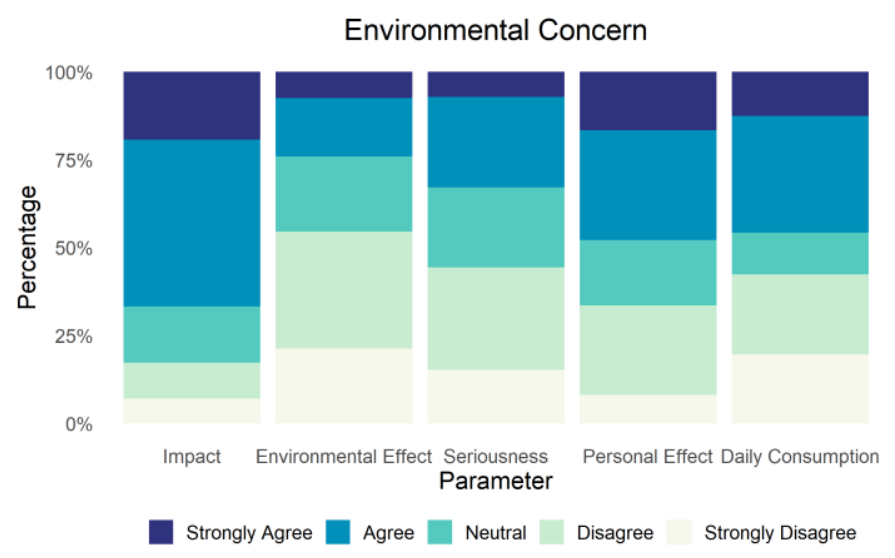

FIGURE 4: GRAPHS OF RESPONSES MEASURING THE OVERALL ENVIRONMENTAL CONCERN OF NAPKIN CONSUMPTION.

and that napkin consumption does have an environmental effect, in the long run things will not balance out.

\subsubsection{Measuring Emotions}

The level of emotions felt in each scenario was determined based on the quartile range of the reported intensities of each emotion. Strongly felt emotions display an intensity greater than or equal to one for the first quartile. Moderate emotions report an intensity equal to one for the second quartile. Slightly felt emotions show an intensity of zero at the second quartile and an intensity greater than one for the third quartile. Finally, emotions with an intensity less than or equal to one at the third quartile were not felt at all. The results for the intensity of emotions related to each dispenser design are graphed in Figure 5.

Overall, the emotions dominating the positive information message were interested and encouraged, followed by surprised, satisfied, proud, joyful, skeptical, and guilty. For the negative information message, the strongest emotions were interested and surprised. Respondents were moderately guilty, worried, upset, and frustrated, and slightly skeptical and encouraged. In the feedback intervention, the strongest emotion felt was interested, while respondents were moderately satisfied and slightly encouraged and surprised. It was expected that respondents would not have strong emotional reactions to the control messages. While this was true for the blank dispenser (only moderately feeling interested and satisfied), it was not true for the field control with the default manufacturer message, in which respondents felt strongly interested, moderately satisfied and encouraged and slightly joyful and proud.

In order to compare the positive affect and negative affect between the different dispensers, a two-proportion $\mathrm{z}$ test was conducted. In this test, the respondents who marked the intensity of an emotion as 'moderately' or higher were tallied and compared. The positive affect (PA) is represented by the emotions proud, encouraged, joyful, and satisfied. The negative affect (NA) is described by the words worried, upset, guilty, frustrated, and skeptical. Interested and surprised were considered neutral emotions. 


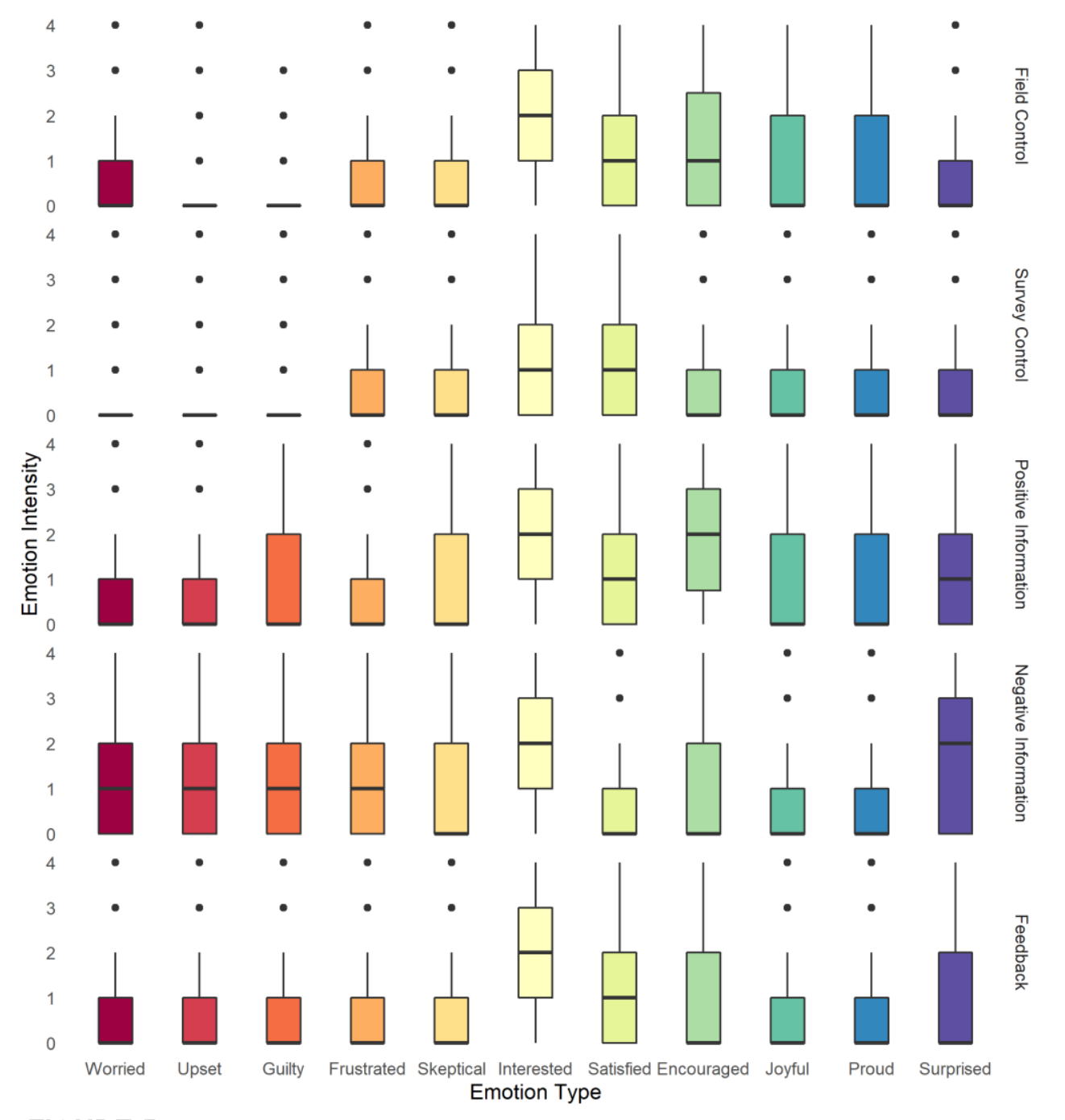

FIGURE 5: INTENSITY OF EMOTIONS FOR THE DIFFERENT DISPENSER DESIGNS

At the start of the survey, before seeing or evaluating any of the dispenser designs, respondents were asked to report their current positive affect and negative affect with the PANAS. The results were used to represent each respondent's mood state in the survey. Respondents who reported an intensity of 'moderately' or higher for all positive emotions (giving a PA score of 8 or higher) or all negative emotions (giving an NA score of 10 or higher) for their current mood state as well as each dispenser design were considered to have unchanging emotions throughout the survey. Overall, 28 respondents were found to have high PA or NA both at the start and throughout the survey. The two-proportion z-tests described in the remainder of this section were conducted both with and without the 28 responses. These responses had no effect on the outcomes on the conclusions of the two-proportion $\mathrm{z}$ test. Therefore, all responses to the survey were kept unmodified and included in the analysis.

The illustration on the field control dispenser was shown to influence positive emotions when compared to the survey control dispenser while maintaining similar level of negative emotions. The NA of the two controls are statistically equal ( $\mathrm{p}=$ 0.597). However, the PA for the designed field control dispenser is greater than that of the blank survey control $(\mathrm{p}<0.001)$.

The negative information intervention is dominated by negative emotions. The NA for negative information is greater than its PA $(p<0.001)$. The NA is also greater than the NA for both control dispensers $(\mathrm{p}<0.001)$.

The positive information message is described by positive emotions. The PA for the positive information is much greater than its NA $(p=0)$. Additionally, the PA of the positive information is greater than that of the survey control ( $p<0.001)$. However, the positive information message's PA is statistically equal to the PA of the field control ( $\mathrm{p}=0.455)$.

The feedback intervention evokes emotions similar to the field control, with slightly more positive emotions as shown by the greater PA than NA $(\mathrm{p}<0.001)$. Feedback has a greater NA than both the field and survey controls $(\mathrm{p}<0.001)$. The PA for the feedback intervention is greater than that of the survey 
control ( $\mathrm{p}<0.001)$ but is equal to that of the field control $(\mathrm{p}<$ $0.001)$.

\subsubsection{Perceived Messages}

The message that survey respondents perceived in each intervention were categorized. The majority of respondents reported that the blank survey control dispenser did not convey any message $(48.9 \%)$. On the other hand, only $22 \%$ found no message for the designed field control dispenser, while $40.7 \%$ related the message to using less napkins, and $22 \%$ cited that the dispenser is better for the environment. For the positive information, $74.9 \%$ respondents perceived the messages to be related to using fewer napkins and saving trees. $78.6 \%$ related the message of negative information to using fewer napkins and the harmful effect of napkin usage on trees and the environment. For the feedback message, only $8.8 \%$ linked the message to feedback on napkin usage over time, while $49.2 \%$ found the message to be that napkins come from trees, and the effect of napkin usage on the environment.

\subsubsection{Effectiveness, Perceived Consumer Effectiveness and Design Evaluation}

The survey also measured whether respondents believed each dispenser design would be effective in changing their individual behavior (Eff) and other peoples' behavior $(P C E)$ as well as the overall design evaluation (Eval). Results to these questions are graphed in Figure 6, graphed on a scale of 0-4: not at all, slightly, moderately, strongly, and extremely.

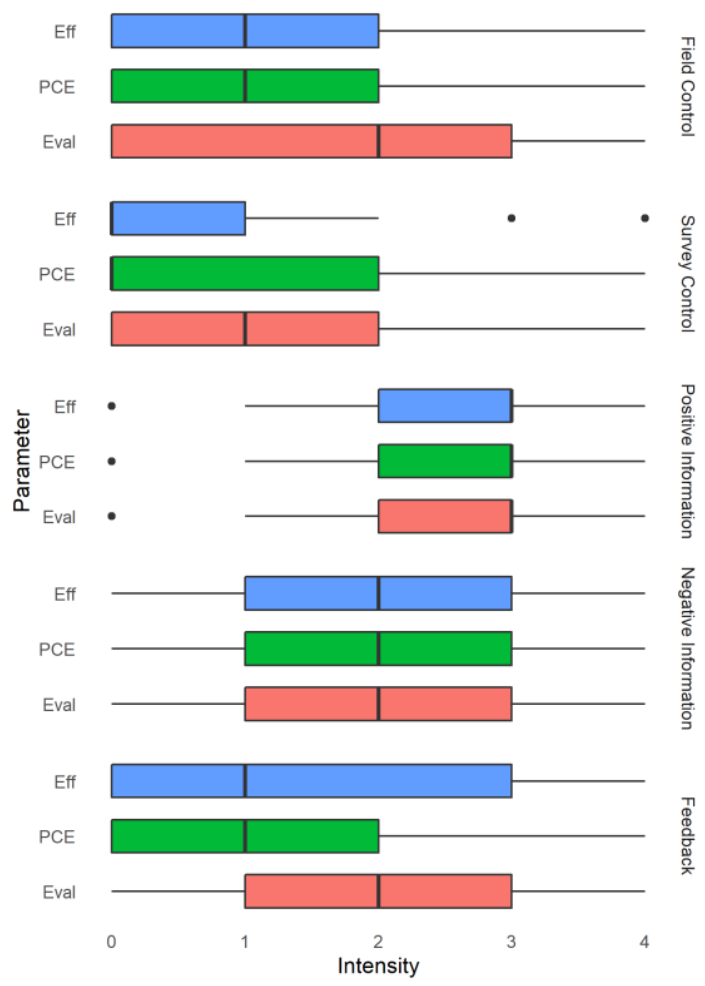

FIGURE 6: EFFECTIVNESS (EFF), PERCEIVED CONSUMER EFFECTIVNESS (PCE) AND DESIGN EVALUATION (EVAL) FOR THE DIFFERENT DISPENSER DESIGNS.
Most respondents did not find the blank survey control dispenser effective at changing their behavior nor the behavior of others (median $=0$ ). On the other hand, they found the designed field control dispenser slightly effective in changing behaviors (median $=1$ ). The field control dispenser was evaluated higher than the survey control in terms of overall design (median $=1 \& 2$ respectfully). The feedback intervention was found to be equally effective to both controls in changing individual and collective behavior (median $=1$ ). The negative information intervention was considered to be moderately effective in changing behavior (median $=2$ ). The positive information was perceived to be more effective than the negative information in both changing individual behavior and the behavior of others (median $=3$ ).

\section{DISCUSSION}

Key findings regarding the original research questions are:

Q1: What are the immediate and longer-term effects of information and feedback interventions on user behavior?

For this study, napkin dispensers with different cognitive interventions were designed and placed in cafés to monitor user paper napkin consumption over the span of several weeks. A survey was also conducted to further understand users' perceptions of each design. The real-world user behavior observed juxtaposed with the insights gained from the survey allowed us to understand the reasoning for the observed effectiveness of each intervention. We found that positive information changed user behavior towards napkin consumption while the intervention was in place. However, the napkin usage increased once the napkin dispenser with the positive information design was removed. This shows that in the context of paper napkin consumption, the positive information intervention is effective in intervening in the user decisionmaking process to encourage immediate sustainable behavior but is not successful in altering long term habits.

Results from the survey shows that respondents viewed the positive information intervention effective in motivating behavior change in both the individual as well as the collective. Since the survey represents respondents' immediate perceptions, this result agrees with the observed behavior in the field study. The success of the positive informative message in altering immediate behavior can be attributed to the individualized message, which gives the user a low-energy action that they can immediately implement (use one less napkin) in order to have a positive effect on the environment (save 544,000 trees a year). However, this message did not impact users enough to alter their habits, so once this message was removed their consumption behavior returned to baseline.

The negative information intervention altered users' paper napkin consumption both while the intervention was in place and for several weeks after it was removed. The immediate effectiveness of the intervention is also demonstrated in the survey, in which respondents viewed the negative informative message capable to motivate them to reduce their napkin consumption. The continued sustainable behavior that was observed in the study after the intervention was removed 
illustrates a potential learning affect that altered user habits and maintained a longer behavior change.

The feedback intervention did not alter any user behavior throughout the field study. Additionally, the respondents in the survey did not perceive the intervention to be effective in encouraging a behavior change. These observations were unexpected as similar feedback intervention designs were perceived to be successful in motivating reduced paper napkin usage in previous studies $[13,17]$. However, further analysis of the survey conducted in this study can elucidate why the feedback intervention did not motivate more sustainable behavior. Results from the survey show that the majority of respondents perceived the message of the intervention to be more informative, reminding users that napkins have a general effect on the environment, rather than the intended message of feedback, showing users the number of napkins used over time. Additionally, the emotions linked to the feedback intervention were similar to that of the control dispensers. Thus, this intervention, which used the illustration of a tree used as a message of feedback, is in reality more informative in its message and more neutral in its emotions. As the behavior observed in the field study and the perceptions shown in the survey, this combination of neutral informative message does not motivate a change to more sustainable behavior.

Q2: What role do positive, negative, and neutral emotions have in influencing users' sustainable behavior?

The effects of positive, negative and neutral emotions on user behavior were investigated through the survey by using a discrete emotion perspective [32]. The emotions were treated as perceptibly different units whose intensity could be rated by respondents in the survey. We chose commonly used emotion labels, such as encouraged and guilty so that they can be easily recognized and measured. The positive and negative emotions were used to attribute an overall positive affect and negative affect for each napkin dispenser design. Strong positive and negative emotions were found to be effective in motivating sustainable behavior in users.

The positively framed informative message evoked strong positive emotions, especially encouraged. This was expected since the positive message encouraged users by showing them that the simple action of using one less napkin can collectively have a large positive impact on the environment. The negative information intervention resulted in negative emotions such as guilt, worried and upset. These emotions were anticipated, as the negatively framed message illustrated the considerable detrimental impact our napkin usage has on the environment. The emotions produced by the feedback intervention were slightly positive, and equivalent to the emotions related to the control dispensers. The fact that the survey respondents rated the emotions of the feedback dispenser and field control dispenser equivalently and found the perceived messages of the two dispensers to be similar is interesting. This suggests that the illustrations of the two napkin dispensers, both depicting bright green leaves, led users to consider them as comparable in both emotions and message.
The slightly positive affect of the field control dispenser with the default manufacture message was contrary to our predictions of a neutral design. The perceived message of the napkin dispenser was also related to the environment and the need to reduce napkin usage. This shows that by simply adding an image of a leaf, users are able to connect napkin consumption to the environment and feel slightly positive emotions. However, this result is not enough to change behavior.

Q3: How effective are positively framed and negatively framed messages in influencing sustainable resource consumption?

The effectiveness of positively framed messages and negatively framed messages can be explained by the perceived environmental concern of paper napkin consumption. In this study, the positive informative message was linked to a change in user behavior while the intervention was in place but did not result in any longer-term behavior change. On the other hand, the negative information intervention appeared to motivate sustainability while the intervention was in the café and correlated to a more permanent change in napkin usage that continued after the intervention was removed. The success of the negative information intervention in the longer-term could be attributed to the users' low environmental concern of napkin consumption at the time of the study.

As the results from the survey show, the environmental concern of napkin consumption is not very high. This low concern can also be observed in the higher intensity of surprised reported for the negative information intervention compared to the positive information. This shows that the negatively framed message presented users with new information that they were not aware of before due to the low environmental concern for napkin consumption. Therefore, the negative informative message communicated to users the gravity of the situation, illustrating the destructive effect of napkin consumption on the environment. The negatively framed message helped convince users of the magnitude of the situation, thereby altering their behavior more drastically. The positively framed message still changed behavior while the intervention was in place since it presented users a simple behavior that can have a positive effect on the environment.

\section{CONCLUSIONS AND FUTURE WORK}

A number of limitations were observed during the course of this study. Due to time constraints, the three interventions were tested in parallel in different locations. For this reason, conclusions on the effectiveness of the dispensers can only be drawn on an individual level and cannot be compared to each other. The different cafés introduce variance in the types of food served, and the number of people who regularly go to cafés, all which may have an effect on napkin consumption. Subsequent studies should focus on conducting all interventions in the same location to eliminate this variance and allow for direct comparison of interventions.

Since this study was conducted in a café setting, there are a number of factors that could not be controlled. For instance, based on hours of observations and interviews with the café staff, 
it was assumed that the majority of customers at each café purchased from the café on a regular basis, and therefore interacted with the dispensers regularly. The behavior of customers that did not frequent the cafes, and therefore may have interacted the dispenser with the intervention only a few times, could not be parsed from those that frequented the café. Additionally, due to the nature of the field study, the specific behaviors and perceptions of the users for each dispenser and how they change over time at the individual level is unknown. Furthermore, since behavior could not be observed on an individual level, the extent to which the observed collective behavior was a result of the design of the dispenser (for instance releasing two napkins at a time instead of one) rather than intentional user behavior could not be differentiated.

As a result of the low environmental concern towards napkin consumption at the time of the study, provoking negative emotions was observed to be more effective in bringing about longer-term behavior change. Future studies can investigate whether a negative intervention increases the environmental concern and if that higher concern results in a reduced performance of the negative appeal and an increased effectiveness of the positive message. Other questions to explore are the length of time it takes for an intervention to lose its effects, after which the original behavior is again observed.

The user behavior observed in this study suggests that cognitive interventions can be effective in motivating sustainable behavior. Evoking emotions also plays a role in shaping behavior. The effectiveness of the type of emotion embodied by an intervention must take into account the level of concern around a particular issue. These key findings can be used to develop a guideline that is used by designers to create products that motivate sustainable behaviors. The conclusions can also be used as a foundation to investigate interventions that can motivate behavior beyond sustainability, such as in health, fitness, and safety.

\section{ACKNOWLEDGEMENTS}

This study was supported in part by the MIT-SUTD International Design Centre. Any opinions, findings, and conclusions or recommendations expressed in this material are those of the authors and do not necessarily reflect the views of the funders. The authors would like to thank Anders Haeggman for his invaluable design expertise, and Toria Yan and Zachary Kopstein for their research assistance.

\section{REFERENCES}

[1] Cor, E., and Zwolinski, P., 2015, "A Protocol to Address User Behavior in the Eco-Design of Consumer Products," Journal of Mechanical Design, 137(7), p. 10.

[2] Berkhout, P. H. G., Muskens, J. C., and W. Velthuijsen, J., 2000, "Defining the Rebound Effect," Energy Policy, 28(6), pp. 425-432.

[3] Lockton, D., Harrison, D., and Stanton, N. A., 2010, "Design for Behavior Change," Advances in Psychology Research, 67, p. 20.
[4] Sohn, M., and Nam, T.-J., 2015, "Understanding the Attributes of Product Intervention for the Promotion of Pro-Environmental Behavior: A Framework and Its Effect on Immediate User Reactions," International Journal of Design, 9(2), p.55-77.

[5] Evans, J. S. B. T., and Wason, P. C., 1976, "Rationalization in a Reasoning Task," British Journal of Psychology, 67(4), pp. 479-486.

[6] Shu, L. H., Duflou, J., Herrmann, C., Sakao, T., Shimomura, Y., De Bock, Y., and Srivastava, J., 2017, "Design for Reduced Resource Consumption during the Use Phase of Products," CIRP Annals, 66(2), pp. 635-658.

[7] Pettersen, I. N., and Boks, C., 2008, "The Ethics in Balancing Control and Freedom When Engineering Solutions for Sustainable Behaviour," International Journal of Sustainable Engineering, 1(4), pp. 287-297.

[8] Serna-Mansoux, L., Popoff, A., and Millet, D., 2014, “A Simplified Model to Include Dynamic Product-User Interaction in the Eco-Design Process The Paper Towel Dispenser Case Study," Journal of Industrial Ecology, 18.

[9] Serna-Mansoux, Livier, Millet, Dominique, Chapotot, Emilie, and Minel, Stéphanie. "For a Sustainable Dialogue: The Green-Use (GU) Learning Cycles Concept." Proceedings of the ASME 2012 11th Biennial Conference on Engineering Systems Design and Analysis. Volume 3: Advanced Composite Materials and Processing; Robotics; Information Management and PLM; Design Engineering. Nantes, France. July 2-4, 2012. pp. 597-606. ASME.

[10] Bao, Q., Burnell, E., Hughes, A., and Yang, M., 2018, "Investigating User Emotional Responses To EcoFeedback Designs," Journal of Mechanical Design, 141.

[11] Lilley, D., and Pettersen, C., 2015, "The Future of Design for Sustainable Behaviour, Revisited," Proceedings of EcoDesign 2015 International Symposium, Tokyo, Japan.

[12] Zachrisson, J., and Boks, C., 2012, "Exploring Behavioural Psychology to Support Design for Sustainable Behaviour Research," Journal of Design Research, 10(1-2), pp. 50-66.

[13] Montazeri, S., Finkbiner, D., Papalambros, P., and Gonzalez, R., 2013, "Save a Napkin, Save a Tree: The Role of Metaphors in Product Design to Change Behavior," International Conference on Engineering Design, Design for Harmonies, Seoul, South Korea.

[14] Montazeri, S., Gonzalez, R., Yoon, C., and Papalambros, P., 2012, "Color, Cognition, and Recycling: How the Design of Everyday Objects Prompt Behavior Change," $12^{\text {th }}$ International Design Conference DESIGN, Dubrovnik, Croatia.

[15] Wever, R., Van Kuijk, J., and Boks, C., 2008, "UserCentred Design for Sustainable Behavior," International Journal of Sustainable Engineering, 1, pp. 9-20.

[16] McCalley, L. T., and Midden, C. J. H., 2002, "Energy Conservation through Product-Integrated Feedback: The Roles of Goal-Setting and Social Orientation," Journal of Economic Psychology, 23(5), pp. 589-603. 
[17] Bao, Q., Shaukat, M. M., Elantary, A., and Yang, M. C., 2016, "Eco-Feedback Designs: A Balance Between the Quantitative and the Emotional," American Society of Mechanical Engineers Digital Collection.

[18] Sohn, M., and Nam, T.-J., 2015, "Understanding the Attributes of Product Intervention for the Promotion of Pro-Environmental Behavior: A Framework and Its Effect on Immediate User Reactions," International Journal of Design, 9(2), pp. 55-77.

[19] Abrahamse, W., Steg, L., Vlek, C., and Rothengatter, T., 2005, "A Review of Intervention Studies Aimed at Household Energy Conservation," Journal of Environmental Psychology, 25(3), pp. 273-291.

[20] Van de Velde, L., Verbeke, W., Popp, M., and Van Huylenbroeck, G., 2010, "The Importance of Message Framing for Providing Information about Sustainability and Environmental Aspects of Energy," Energy Policy, 38(10), pp. 5541-5549.

[21] Obermiller, C., 1995, "The Baby Is Sick/The Baby Is Well: A Test of Environmental Communication Appeals," Journal of Advertising, 24(2), pp. 55-70.

[22] " 544,000 Trees Could Be Saved | Infographics Inspiration."

[23] 2017, "Paper vs. Cloth," Dempsey Uniform \& Linen Supply [Online]. Available: http://www.dempseyuniform.com/wp-

content/uploads/2018/12/dempsey-uniform-paper-versuscloth-table-linen.pdf.

[24] Newton, G., 2018, "Tip of the Week: Replace Paper Towels and Paper Napkins with Sturdier Cloth Ones," Green Newton.

[25] Fang, W.-C., and Hsu, J. Y., 2010, "Design Concerns of Persuasive Feedback System," Visual Representations and Reasoning, pp. 20-25.

[26] Goucher-Lambert, K., and Cagan, J., 2015, “The Impact of Sustainability on Consumer Preference Judgments of Product Attributes," J. Mech. Des, 137(8).

[27] Macomber, B. A., and Yang, M., 2011, "The Role of Sketch Finish and Style in User Responses to Early Stage Design Concepts," Proceedings of the 2011 ASME IDETC, Washington, DC, USA.

[28] Häggman, A., Tsai, G., Elsen, C., Honda, T., and Yang, M., 2015, "Connections Between the Design Tool, Design Attributes, and User Preferences in Early Stage Design," Journal of Mechanical Design, 137.

[29] Ellen, P., Wiener, J., and Cobb-Walgren, C., 1991, "The Role of Perceived Consumer Effectiveness in Motivating Environmentally Conscious Behaviors," Journal of Public Policy \& Marketing, 10, pp. 102-117.

[30] Watson, D., Clark, L. A., and Tellegen, A., 1988, "Development and Validation of Brief Measures of Positive and Negative Affect: The PANAS Scales," J Pers Soc Psychol, 54(6), pp. 1063-1070.

[31] Richins, M., 1997, "Measuring Emotions in the Consumption Experience," Journal of Consumer Research, 24, pp. 127-46.
[32] Ekman, P., 1992, “An Argument for Basic Emotions," Cognition and Emotion, 6(3-4), pp. 169-200. 